\title{
Student Reporting Abroad: A journalism project built on internationalisation
}

\section{ABBSTRACI}

This article updates research by the writer on overseas reporting trips for Australian Journalism students, conducted since 2000. It describes changing educational contexts, with expanded internationalisation and work integrated learning. A precursor of both, the trips project provides a Faculty-level model for implementing such changes. Previous research, to 2008, recorded 60 students making nine field trips, to Southeast Asia, China, Papua New Guinea or Europe. Participants working as foreign correspondents for campus-based media outlets, would apply that experience to theoretical work, e.g. on international journalism or inter-cultural issues. The research has supported arguments for internationalisation of the curriculum, positing that intensified experience will concentrate the mind, improve skills and stimulate reflection. The present work goes further, with more individual and detailed probing of student responses. As a case study, nine participants travelling to South-east Asia and Europe in 2012 documented their experience and their reflective work. The investigation concludes such travel programmes can be highly effective in core learning.

Keywords: curriculum, field trips, internationalisation, journalism, work integrated learning

\section{LEE DUFFIELD}

Queensland University of Technology

7 HE EDUCATIONAL times have brought themselves up to date with a programme of overseas reporting trips for Australian Journalism students, operating since 2000 - as Higher Education generally becomes increasingly internationalised. Under the programme, at the Queensland University of Technology (QUT), advanced level students work as 
correspondents for campus based media outlets, to develop their professional skills under pressure, and then reflect on their experience and conceptualise it. The students' home course attracts higher standard matriculants (Queensland OP5, ATAR 92.25) with a strong record of graduate employment. The programme is called Journalism Reporting Field Trips (JRFT). The present article will bring up to date scholarly reports by the writer on the evolution of the project, in its context of two educational movements: Internationalisation of the Curriculum in Higher Education, and systemic adoption of the principle of Work Integrated Learning.

It will assess the most recent trip in the JRFT series, and go further than the previous reports in assessing impacts on individual students. This journey by ten students from 27 June to 16 July 2012, is proposed as a case study demonstrating key aspects of the JRFT program as a form of learning. The students were briefed to report on impacts of the European financial crisis, travelling to Bangkok, Athens, Brussels and Paris. They would encounter strong learning, and concurrently maintained working diaries, towards a summary of activity at the end, where they would individually review the experience and assess its value as professional preparation.

They reported that the project showed them the high importance of being backgrounded on the news, and of preparedness for inter-cultural settings. Travelling and keeping a focus on the news product would be called a challenge, but rewarding for quickly improving journalistic skills. Teamwork was emphasised, most appreciating others' help in managing and evaluating their work. Student reports made frequent reference to literature related to their tasks, most notably with ethical issues encountered. All had completed standard coursework units on journalistic ethics, drawing on applied texts that would discuss the widest range of dilemmas and cases (e.g. Hirst and Patching, 2005; Pearson, 2004; Tanner et al., 2004). They identified issues they saw as part of the general scheme of ethical conduct, e.g. 'balancing' a contentious political story in Greece, or wrestling with fair use of material given in confidential briefings.

The journey followed a pattern now well established: Stays would be of at least three days in each location where work was scheduled; one or two meetings were pre-arranged for each working day, where the whole group, or some members could interview locally-based informants; the programme remained flexible with encouragement to expand on this by finding new informants and 
stories. Diversions from the theme of the financial crisis were possible, mostly for features material. At time of writing, a new JRFT was being organised for the South Pacific, to Noumea, Port Vila and Auckland in mid-2014.

\section{Context of Journalism Reporting Field Trips}

In 2000 the JRFT program's immediate theoretical context was the movement for Internationalisation of the Curriculum in Higher Education. This had two parts: an enduring faith in intensity and diversity of experience, to advance awareness and personal growth, especially in vivid inter-cultural contexts; and secondly, growing interest on the part of universities in enriching and extending the range of their students' programmes. In what was described often as the advent of 'non-ideological' thinking about overseas learning, the catchcry became that graduates would need to be able to practise in their professions anywhere in the world, and the universities would aim at providing students with a rich percentage of their study time abroad. Goals were adopted, to provide routinely 10-20 percent of students some study overseas. By 2013 the scope and intensity of the drive for internationalisation had expanded radically, and had developed in qualitative terms. Much larger numbers of undergraduate students and researchers were being located outside of their home countries, engaged in diverse learning programmes and research, with transformative use of digital tools for management and study, together with an expanding commercialisation of education across the board.

The Australian programme under study, JRFT, took a lead in the early phases, by studying the impacts on individuals, and the preparation of individuals to take part in the new, internationalising forms of learning for a professional life. Internationalisation as the context, was being defined, as by De Wit (2002), in terms of a 'process of integrating an international/intercultural dimension ... into academic institutions'. Knight (2013, p. 3), a leading scholar in internationalisation of education as a process, describes it as having been an evolving practice, with Stage 1, from the 1980s a 'first generation' involving expanded mobility of students, staff and scholars, working mainly in established institutions; and Stage 2 a time of more provider and programme mobility, with twinning of institutions and franchising of courses, together with pervasive online management of data for learning and research. Arriving at Stage 3, the third 'generation', students are now in the era of educational 'hubs': varied kinds of research concentrations, educational centres or training enterprises 
drawing on heavy governmental and private investment, with universities much involved - all with a highly cosmopolitan personnel base.

\section{Globalisation and internationalisation of the curriculum}

Internationalisation, as often explained in the literature and readily seen, is intimately linked with the globalisation process in the world economy and society, founded to a high degree on technological change, which has enabled rapid liberalisation of finance and trade, and which has aided in the growing movement of people across frontiers. Knight earlier, for example, saw internationalisation linked with expanding electronic delivery modes both domestically and internationally; along with increased international academic mobility of students, professors and programs (Knight, 2003, in Breton and Lambert, p. 82). A pattern of commercial investment had begun to set in.

The Organisation for Economic Cooperation and Development (OECD) had become sharply aware of a massive trade developing in educational resources by the start of the last decade, when for 1999, it estimated the value of trade in educational services at US\$30 billion (Knight, 2003, in Breton and Lambert, p. 84). It has since monitored this trade, measuring growth at 12 percent a year in the first decade after 2000. As an OECD sponsored research activity, Lim and Saner (2011) analysed statistics that established extremely high returns being obtained from private, corporate and public investment. Their work showed a doubling in the number of international students worldwide between 1999 and 2007, to nearly three million; and identified a new trend towards much stronger corporate ownership, provision of services and exercise of power over educational policy.

\section{Work Integrated Learning}

An aspect now is the drive towards funding and commercialisation of more applied research, as distinct from curiosity based or 'pure' research; and in teaching and learning, the embrace by universities of Work Integrated Learning (WIL). Where the thrust of the WIL idea is to link academic learning to demands of industry in the new economy; it assists with the justification for deployment of resources on projects such as JRFT, as an intensified professional preparation in working situations, most often involving contact with practitioners. JRFT participants receive pre-trip briefings from practitioners, work with others, as informants, mentors or interview subjects, and 
will sometimes complete short internships in overseas news rooms. Where universities call for a percentage of student study time to be spent overseas, and for active links with industry, mobilisation schemes such as the JRFT facilitate it, at the crucial level of individual learning.

Cooper et al. (2010, p. i) provide a thorough treatment of WIL, being taken up in educational doctrine across the university sector in several countries including Australia. They identify changes in industry associated with globalisation as the driver for change, in the form of integration: 'The demand for work-ready graduates, who are familiar with organisational practices in the workplace is increasing ... With the globalisation of higher education and the cultural and linguistic challenges this brings, WIL has become a core strategic issue ... a process of integration between workplaces, higher education institutions, government, business and industry.'

Academic work nearly a decade ago had identified much work-based learning going on, with in any one year one third of students 'learning out in workplaces'. This would be unsurprising; practicum has been essential, for example, in many disciplines notably Engineering (see for example Keleher et. al., 2010), and in the present case Journalism. However the extent of new demand called for a systemic expansion, providing more inter-institutional partnerships with industry, with focus on an integration of theoretical, practical and life knowledge. It would reduce competitiveness between the "two learning environments', the practicum and theoreticum, requiring "due regard to theory and research generated evidence" (Cooper et al., 2010, p. 2):

We have defined Work Integrated Learning as a complex integration of the learning that happens in the higher education and workplace context, not simply as a cross-fertilisation or transfer of theory and practice, but as a whole learning experience that requires conscious planning and effort on the part of all involved, from university policy makers and host organisation managers to professional accreditation bodies and students. (Cooper et al., 2010, pp. 12-13)

The omission of academic staff, the teachers, from such formulations is common. Extensive workplace learning provided by academic departments before the advent of the WIL policy thrust, often misunderstood by its critics, would be characterised as under-resourced, 'project-based', 'cottage industry', with two central failings: it lacked coordination and consistency of standards, and in general was 'under-researched and under-theorised' (Cooper et al., 2010, 
pp. 21-22): 'Work experiences that are not integrated into the academic curriculum, do not promote learning through a process of reflection and analysis, do not provide students support and in which the learning is not situated, constructed and experiential are not Work Integrated Learning (Cooper et al., 2010, p. 43; also citing Orrell, 2005).'

The situation had evolved rapidly, where globalisation had generated a new economy which in turn created demand for learning overseas, and learning in workplaces. It called out to be managed, and would remain complex, with at base the agreed need to produce educated minds adaptable to a new economic order. A national review of activity in Australia on WIL, advertised as its first premise: 'The WIL experience is highly contextualised and impacted by the expectations of students, employers, the professions, the university and government policy (Patrick et al., 2008).'

The 'practicum-theoreticum' link is a well-worn subject in the professional disciplines like Journalism; see for example Deuze (2009; quoted in Woolley, 2013, p. 4) and others noting a perceived 'binary opposition'; academics identifying with a so-called academic approach, practitioners wanting a 'practical' approach. The present JRFT case presents as a model for resolving such tensions. The program involves several practitioners; it nevertheless is embedded in study, and has been consistently referenced to pedagogical thought and an ongoing review of developments in higher education, specifically internationalisation (Duffield, 2004, 2007a, 2007b, 2008). As well as successive review articles based on the field trips, the research includes a collegiate exercise on developing a new university subject (Duffield, 2010, 2011a), and also a short study of institutional policy and individual experience of International Students in doctoral programmes (Duffield, 2011b).

The advent of 'WIL' as a doctrine and procedural innovation saw a range of courses introduced at QUT, providing final-year elective options, and new Faculty-wide subjects to fulfill these options, structured around the work-based learning principle. Two would be for work overseas. The subjects provided a framework to ensure thorough preparation for the travel program (using a Gantt chart for the production schedule), attention to risk management, teambuilding, and due reflection on practice. The JRFT, which provided full-subject credit for elective subjects, and partial credit for other, established ones, easily fitted into the structure. The WIL suite of options opened with significant funding for student travel bursaries, and for a central office to coordinate WIL 
activity. Participants in the 2012 reporting field trip received some travel assistance from this pool, (A $\$ 650$ for each student, a little over 12.5 percent of individual outlay for the journey).

Self-funding by students has been queried as inequitable. It is central to Study Abroad, a part of the movement towards Internationalisation of the curriculum, where fees would be paid by learners, not equalised between institutions. Exotic travel is common for the student generation and devoting travel money to learning is seen as an investment. Students in the JRFT pay their own costs sometimes with small Faculty encouragement bursaries, and assistance in setting up budget-priced itineraries. The programme enables students to take part by working on production support at the home desk, viz some with young children. Use of always more advanced communication technologies, e.g. for international teleconferencing and interviewing, will inevitably see more being done from a home base, in a context of 'Internationalisation at Home' (See Beelen, 2007), while preserving the need for competency on the ground in far locations. The JRFT programme is sustained by well-developed procedures for travel approval, and free, comprehensive travel insurance provided by the university.

\section{Journalism Reporting Field Trips and research}

Research by the present writer, as coordinator also of the JRFT, breaks from the concentration on institutional or systemic or management concerns - the study of structures and functions - found in much of the literature on Internationalisation of the Curriculum, and of WIL. Its main interest is the study of students as individuals in the shifting contexts of internationalisation in education. Their experience is important as they are seen as both learners and themselves key contributors to knowledge, and then as professional resources. Foundational ideas in WIL do assume that learners in an integrated university-workplace system will experience developmental growth, and further study may demonstrate how that occurs. The goal is a depth of knowledge of an 'integrated' kind, a settling of the 'differences between dec- larative and functional knowledge' (Cooper et al., pp. 40-41, quoting Biggs, 1999).

Monitoring of the JRFT to date has registered 12 tours of 10-20 days, with 81 students covering in all 12 countries of Europe and the Asia-Pacific region. These have been reported on descriptively and in terms of their broader journalistic and educational contexts (See Duffield, 2008, 2007a, 2007b, 2004; 


\begin{tabular}{|c|c|c|c|c|c|}
\hline Year & $\begin{array}{c}\text { Expressions } \\
\text { of interest }\end{array}$ & $\begin{array}{l}\text { Number of } \\
\text { participants }\end{array}$ & Itinerary & $\begin{array}{l}\text { Number of } \\
\text { days away }\end{array}$ & $\begin{array}{l}\text { If accompa- } \\
\text { nied by staff }\end{array}$ \\
\hline 2000 & 8 & 5 & Indonesia (Jakarta) & 10 & - \\
\hline 2001 & 16 & 8 & $\begin{array}{l}\text { Singapore/Malaysia } \\
\text { (Penang,KL) }\end{array}$ & 14 & - \\
\hline 2002 & - & - & - & - & - \\
\hline 2003 & 22 & 10 & $\begin{array}{c}\text { EU (Bonn, Frankfurt, Strasburg, } \\
\text { Cologne, Maastricht, Brussels, } \\
\text { Paris) }\end{array}$ & 20 & Yes \\
\hline 2004 & 13 & 13 & HK/China (Beijing) & 14 & - \\
\hline 2004 & 5 & 5 & PNG (Port Moresby, Madang) & 10 & - \\
\hline 2004 & 3 & 3 & PNG (as above) & 10 & Yes \\
\hline 2005 & 4 & 4 & $\begin{array}{c}\text { EU (Rome, Geneva, Bonn, } \\
\text { Brussels, Paris) }\end{array}$ & 20 & - \\
\hline 2006 & - & - & 一 & - & - \\
\hline 2007 & 4 & 4 & $\begin{array}{c}\text { EU (Frankfurt, Bonn, Brussels, } \\
\text { Paris) }\end{array}$ & 20 & Yes \\
\hline 2008 & 8 & 8 & $\begin{array}{c}\text { EU (as in 2007); HK, China, } \\
\text { Singapore }\end{array}$ & 19 & Yes \\
\hline 2009 & 13 & 9 & PNG (Port Moresby, Madang) & 12 & Yes \\
\hline 2010 & 3 & 2 & \begin{tabular}{|c|} 
EU Brussels, Spain (Pamplona, \\
Madrid)
\end{tabular} & 14 & - \\
\hline 2011 & - & 一 & - & - & - \\
\hline 2012 & 14 & 10 & $\begin{array}{l}\text { Thailand (Bangkok) EU } \\
\text { (Athens, Brussels, Paris) }\end{array}$ & 20 & Yes \\
\hline TOTAL & 113 & 81 & & & \\
\hline
\end{tabular}

Woolley 2012). As a measure of outcomes, grades in assessment for course credit associated with the field trips have been high, and careers outcomes for participants well above average; though many students attracted to the programme have been routinely high achievers. Table 1 sums up the range of activities.

A focus of the reporting and assessment of these exercises has been to register and interpret the experience of the participants. As reported in 2008 (Duffield, 2008) monitoring has been through close observation by the writer as an organiser and sometimes participant, backed by notes made during debriefings of students, with at times distribution of questionnaires. Reflective work by the students, e.g. review essays, was also consulted. 
Returning students questioned about the programme almost unanimously report they have obtained more concentrated learning from it; have responded to the stimulus by working conscientiously, e.g. in preparing for interviews, and perforce take better account of inter-cultural issues. There is broad accord each time that their focus on tasks intensified when on the road, and they developed better self-sufficiency. In regard to communication principles in play, the students reported a heightened sense of striving to communicate with audiences in Australia, concerned how they might provide adequate backgrounding. Where a questionnaire was used, e.g. returns from eight of the ten participants in 2003, students rated the programme's value to their individual scholarship and preparation for journalism highly at 6 or 7 on a seven-point scale.

The record attests to the situation being an outlet for students' resourcefulness, for example where students can speak a local language: parleying camera access to the Frankfurt stock exchange; making radio programmes with expatriates in South-East Asia, in German and English; reports on politics and gelati-tasting in Italy; a French speaker's feature on Brussels' Tintin museum. Reports by a student with a nursing background on health services in Papua New Guinea led to a small-scale medical aid project.

However, the opportunity to examine student experience in the context of internationalisation calls for yet more ingenious approaches, to more thoroughly appreciate how much is being learned, and how; and it needs to continue through approaches suitable to research with such small groups. In the case of the 2012 JRFT reported on here, the collaboration of students was obtained through their systematic re-committal of work done and self-review of performance in the field, in a package of documents, as part of the formal course-work assessment; see following section.

Some assistance in the task of delving into the quality and meaning of participants' experience has been provided also by Wooley (2013) in a study of 'Vietnam Reporters', a venture involving ten students from the University of Queensland similar to the JRFTs. In this case the student group included some first-year students, and the work output demanded a larger quota of reports per student; although this was with the assistance of technical staff, and so did not as much replicate the experience of field correspondents. Products were offered to mainstream media outlets, e.g. Australian ABC, APN newspapers and Vietnamese television V-TV, seen as placing additional pressure on the trainees. 
Analysis of this work was based on questionnaires completed by all participants, before and after the tour, and fortified by a computer assisted analysis of their journalistic products, using key words, which detected an increasing depth, comprehensiveness and 'sophistication' as time continued in the field, the trend being away from simple, impressionistic feature material towards more analysis. The investigation confirmed conclusions obtained from the review of successive JRFT exercises: Students had a retrospective realisation of how backgrounding is crucial, thinking they should have taken better advantage of preparatory sessions; they realised the significance and value of inter-cultural knowledge and language skills; they more thoroughly appreciated the need for 'technical' capacity ('hands-on' competency with facilities and equipment; application of editorial sense and production values under pressure); and the tasks came to be seen as better suited for advanced students, rather than initiates from lower levels.

\section{Study of the 2012 Journalism Reporting Field Trip}

By 2012 the pattern of understanding of the field trips programme was well settled. It had been determined through time and error that the optimum size and composition of groups would be of 3-10 participants, at advanced levels in their courses, preferably with relevant foreign language experience, though not necessarily well-travelled, (past recreational travel often providing no preparation for work travel). Ten students travelled to Bangkok, Athens, Brussels and Paris, in June and July 2012, reporting on impacts of the European financial crisis; accompanied by the investigator as the team leader and mentor. It was determined that assessment of the exercise would attempt to go further than in previous cases, to delve more thoroughly into the students' register of the experience and their reflective thoughts on it. To this end, the students agreed to the use of some of their coursework assessment materials for evaluating the exercise.

\section{Methodology and procedure}

Nine students (after excluding one doing a different academic programme) were required to keep a diary; seven added a reflective report on objectives, experience and outcomes, as part of the course-work in one subject. The nine voluntarily handed over their documentation for this research; and while the work could not be received anonymously, it is reported anonymously and they are coded A-J. Qualifications would apply to interpreting documents 
prepared in part for subject assessment, most notably that students might feel impelled to confirm the objectives of the operation as cited by the team leader and assessor: stimulus for learning, achievement, fulfilment. However the fact of providing a formal response, with clear terms of reference, due transparency of the process, and use of backgrounding texts to frame understanding, would work against distortion. No part of the research appraisal would examine work worth more than 10 percent of the actual numerical value for one subject. Added to that, the procedure was undertaken with a sense of necessity, to get information at some depth on the student experience. That was because previous attempts to interrogate participants in JRFT had been somewhat frustrated by the small numbers, especially with some not taking part.

For a 'WIL' subject in which seven of the nine students were enrolled, called Creative Industries Project 1, the assessment requirement was for an advance proposal on the travel and research project, and a similar, retrospective review statement, both providing 10 percent of the marks. The latter, called Assessment Item 3, was used for this research appraisal of the programme. It was set as a reflective report on the exercise, of 1250 to 1500 words, with specific reference to be made to teamwork aspects of working in the field on news coverage, and to ethical considerations encountered. In each case the students wrote a narrative of the experience with commentary on the significance of selected actions and decisions they had made in providing news coverage. These followed a stipulation to provide evidence or at least rich examples to support any observations, and make any generalisations or principles elicited from that work. The students had received results for the advance proposal, Assessment 1, all but one in the Distinction range. The main assessment for the subject, Assessment 2 worth 80 percent, was appraisal of journalistic work in the field. Results of this main assessment had not been determined when the students submitted Assessment 3, nor when Assessment 3 was being used as part of the current research. In addition the nine travellers wrote a field diary, setting out their activities and personal responses, the diaries contributing to the evaluation of the program.

\section{Outcome of the inquiry}

A summary of responses is that the participants after the working journey of nearly three weeks' duration, endorsed the premise of the exercise, that 
novel experience under the stress of reporting might be found 'daunting' but productive in improving their journalism. As well:

- The members of the group became task orientated in approach; putting their focus on the product over the process.

- They identified an interaction between individual drives and being on a team; the latter indispensable to making progress.

- The reports from this group showed a keen concern with ethics in journalistic work; raising some questions over actual situations encountered.

- The last two points related to preparatory reading, which provided a context of theory or principles, and assisted with making sense of the experience overall.

Detailed responses, using analytical statements from four of the students, which were the most expansive, and calling in supporting statements from others, are as follows.

First response: Student E emphasised success in individuals being able to work autonomously within guidelines and directions, because of team members forming a support base: "We were consistently able to overcome obstacles including at times lack of resources, and confidentiality agreements [with briefing sources] ... and maintain a "results focus" by leveraging each team member's individual expertise.'

Others in support of the above view: Student G: 'I tried to cover too many topics in one story but learned quickly and the last story was best. It would be impossible without assistance of the entire team. .. The team used its expertise of previous cities to improve its ability to communicate internally....' Student D: 'We had set out individual goals and proposals for stories but soon realised team work and communication was a necessity... With new stresses of working in a foreign environment we constantly needed to check each person's movements ... I believe I improved my broadcast skills, increased my journalism portfolio and improved interviewing skills - able to obtain quotes from two Athenians despite language barriers. I still need to work on time management.'

Second response: Student $\mathbf{H}$ attached value to participants being forced to improvise, because of the new and extreme working environment: 'It was not possible to plan for everything.' Help was obtained through 'cohesion of the group', but there was limited time for 'touching base' to confirm story ideas and sources... 'An issue that hindered my journalist performance was 
confidence in my abilities....' Student $\mathrm{H}$ determined that while group members might struggle at an emotional level with disruption and uncertainty, they could derive a pervarsive benefit in terms of improving their journalism: It was 'challenging', but aims were still achieved, such as 'to develop interviewing skills', 'build on ability to find stories or angles', 'build speed and accuracy in writing' ... Those goals were met in new ways under new pressures. 'Issues with time pressures or cancelled interviews encouraged flexibility and creativity and being thrust into a new environment developed my confidence as a journalist.'

Among others in support, Student B set out a firm framework following the text on teamwork, Horine (2005), for example identifying the value of clear communication of team members' responsibilities, or attaching priority to making accurate estimates of the work to be done. This participant determined that in the event, in the situation of a reporting day, detailed pre-planning using the Gantt timeline, 'did not go 100 percent to plan'; yet team work sustained individual efforts, and 'I gained insight into other people's passions'. In this case a student conscious of individual welfare as a priority, and disposed to rely on process and procedures to ensure performance, yielded to the need to improvise as well, to manage the fluctuations and vagaries of the actual news of the day.

Third response: Student $\mathbf{J}$ was the strongest achiever in doing their journalism and assisting others, grasping the potential of the situation: 'The field trip was an opportunity for the team to practise skills in a simulated realworld environment - including in difficult circumstances with tight deadlines. ... Much like the real world, the success of this journalism project should be determined by the quality of the work produced... I feel that most of the team has a high opinion of the project's outcomes...' Expressions of good satisfaction with the product were very common with this group, taken as an indication of major interest in the task. The quality of journalistic material worked on became a guide for evaluating their project.

Fourth response: Student $\mathbf{C}$ considered approaching tasks in a foreign environment 'nerve-racking'. For example withholding from publication a report on media freedom in South-East Asia until after leaving Thailand, in case of any trouble with the authorities while there, caused uneasiness. 'The "consensus" of the story was that journalists' obligations in Thailand are similar to those elsewhere, but without a completely democratic background their 
work is not as trusted as some of their Western competitors...' The account of other reports produced a similar theme of overcoming fears to produce credible reportage, with the help of good research. For example, writing from unattributable briefings at the European Commission required the journalists to give information and make assessments on their own authority: 'It was a task which could have been daunting but I feel most in our group had done adequate research on the Greek debt crisis and had done prior research on the recent elections and political situation.'

Others supported this view, that the task was demanding and something very new, but manageable with preparation, and one that in the act of doing the journalism, engendered better ability to do more. Student A: 'The experience was at times a bit daunting given the unfamiliar environment, but it was also incredibly rewarding. I learned to have confidence in my own abilities and to accept and appreciate constructive feedback.' Student I: 'The field trip gave me real world experience and experiences I would never have had access to on my own. It allowed me to produce work for my portfolio to hopefully make me more employable. It refined and extended my practical journalism skills overall.'

\section{Points derived from the participants' written assessments of the project} Ethical practice was a preoccupation, with concern about a set of issues encountered:

- The handling of non-attributable information from briefings at embassies or the European Commission. How could information be fairly used without attributing to a source; and what to do if the information proved wrong, or was inadvertently mishandled?

- Avoiding censorship in Thailand. In a first encounter with a system not fully open to free flow of news, what are fair protocols for selfcensorship; how do you calibrate risk against the value of a story?

- Reporting the case of a young Australian woman robbed in Greece. Meeting this young woman stranded without passport or money was the chance to lend a hand and obtain a human interest story. When the person later became distressed, the journalist had to debate disturbing her to ask for some information missed in the original interview.

- Balancing a story about the Syriza political party in Athens, and handling a demonstration. The party office could not provide an 
English speaking official at short notice, for radio, providing a 'balancing' problem. This was covered by getting a 'neutral' foreign correspondent from Germany to characterise the party's line, and by paraphrasing it in the reporter's own script. This student enterprisingly found out about a left wing street demonstration, where the reporting group was confronted by a suspicious and threatening security detail. The journalists had identified themselves to the rally's organisers, who called off the guards; the incident provided a lesson in following an ethical approach, or at least exercising due care.

The 'being there' message was noted; working across cultures found to be more accessible if you take to the field, to see what is happening, obtain information 'unprocessed', assess eye-to-eye the credibility of those offering explanations. The use of online sources, as the respondents averred, was reduced in perspective, mainly to be employed for updates, checks and background for vivid field material. Sometimes access to the internet was impeded by technical obstacles not previously encountered by the students. A different reality and quality of information was being obtained, for example by a Business and Journalism student, surprised to find people who contradicted a pre-conceived story on the pain of economic dearth: "I was told by a Greek; "Greeks just complain too much."”

Australian angles and talking to Australians. The large significance of cultural differences is understood when the differences are temporarily removed. As noted by respondents, it eased the stress of intercultural communication to obtain interpretations in nuanced home language from Australian intermediaries. The Australians in question would have strong standing to provide news, i.e. not just any Australians. They were, for example, a senior archaeologist in Athens, the Australian Ambassadors to Greece and to the European Union, an Australian business leader in Brussels, and the Australian traveller in distress.

Opportunities to be realised from a vivid cultural and sensual change of scene; referred to by a specialist photographer in the reporting group, Student I, who, responding to the stimulus, produced galleries of intriguing and beautiful images.

Tough going. Experience of the reporting grind; time-zones, deadlines, long hours, feeling 'burn-out'; having to concentrate while moving about, with constant focus on the product. This aspect of news correspondent work 
was described in terms of rewards, like learning experiences for a journalistic career, and success getting good work published. The experience was seen to replicate the work and job satisfaction of professionals.

Reference to texts was common and well managed to illustrate concerns of the learners/participating journalists. Various texts supported students' analyses of their work as members of a team, principally the set text for the WIL subject (Horine, 2005), and texts relating to team work in business (for example, Puccio GJ, 1999). Similarly discussion of professional ethics and decisions that were taken, were referenced to texts from the Journalism curriculum (see Hirst and Patching, 2007; Frost, 2010; Grace, 1998). An important observation was to be drawn from this. The reports by participants indicated an informed consciousness of principles underlying their professional practice, in their readiness to generalise from immediate dilemmas and render them in abstract. The participants had instructions to make reference to background reading; significantly this was done with application, to make sense of experience that was striking, new to them and often confronting. The 'thinking on your feet' encountered when doing journalism can be related to settled thought, in a process that assists overall understanding.

\section{Conclusions and points for discussion}

Under investigation, the Journalism Reporting Field Trips are seen to have intended impacts as a form of professional preparation. They produce a strong flow of journalistic materials that will stand up well to appraisal, usually of a good near-professional standard. Participants, consulted, offer an all but unanimous judgment that the experience was a stimulant for personal and professional development. The attempt to obtain a more intense and precise record of experience from participants in the 2012 exercise gave indications of the field trip experience functioning as a platform for reflection, and for realisation of journalistic principles. Theoretical posits would be enacted in practice, and might be used in interpreting experience.

As with professional journalism, the work of this group was task orientated, the participants reporting on their priorities and achievements principally in terms of obtaining the news and publishing it. They evinced faith in teamwork, stating that this required commitment and intent, but gave rewards in terms of support at different levels, for achieving the task. There was also a concern to be engaged in best practice in regard to ethical conduct of their 
journalism, informed by guided reading. The Journalism Reporting Field Trips programme is firmly encased in the movement for Internationalisation of the Curriculum in Higher Education, in providing a strong international and inter-cultural component in the strategic final year of a sought-after Journalism course. It aids materially in equipping graduates to be able to practise their profession anywhere in the world. Similarly the programme has a place in Work Integrated Learning due to effective interaction between 'practicum' and 'theoreticum'; the participants in intense activity doing journalistic work are engaged with practitioners and their business; they give evidence of learning and change, and may think it through in abstract.

\section{References}

Beelen, J. (Ed.) (2007). Implementing internationalisation at home. EAIE Professional Development Series for International Educators, \#2. Amsterdam: European Association for International Education (EAIE).

Biggs, J.B. (1999). Teaching and quality learning at university. Buckinghamshire: Society of Research into Higher Education and Open University Press.

Cooper, L ., Orrell J. \& Bowden, M. (2010). Work integrated learning: A guide to effective practice. New York: Routledge.

De Wit, H. (2002). Internationalisation of higher education in the United States of America and Europe. Westwood CT: Greenwood.

Duffield, L. (2011a) Media skills for daily life : Designing a journalism programme for graduates of all disciplines. Pacific Journalism Review, 17(1), 139-154.

Duffield, L. (2011b). Successes and stresses : A case study on relations between international higher degree students in Australia and their universities. International Unity in Diversity Conference, Rydges Southbank Townsville Hotel, Townsville, North Queensland.

Duffield, L. (2010). Investigating the process of teaching and learning principles through practice: a case study on collegiate action by media practitioners and teachers, designing a skills-based learning program. Journalism Education Association Annual Conference, 24-26 November 2010, UTS Sydney.

Duffield, L. (2009). A news story as big as a doctoral thesis? Deploying journalistic methodology in academic research. In Communication, Creativity and Global Citizenship; refereed proceedings of the Australian and New Zealand Communication Association Conference 2009, ANZCA and University of Canterbury, Queensland University of Technology, Kelvin Grove, Brisbane, pp. 581-602.

Duffield, L. (2008). Student reporting abroad: An international programme called Journalism Reporting Field Trips. Pacific Journalism Review, 14(2), pp. 102-122.

Duffield, L. (2007a). Journalism education: Journalism reporting field trips and internationalisation of the curriculum. Public Right To Know Conference, Centre for

PACIFIC JOURNALISM REVIEW 20 (2) 2014221 
Independent Journalism, UTS Sydney, 24-25 November, University of Technology of Sydney, Australia.

Duffield, L. (2007b). Journalism Reporting Field Trips: Practical work overseas brings home to students 'real world' implications of their professional preparation. In Effective Teaching and Learning Conference - 2007: Preparing Students for Work in the Real World, 1 \& 2 November, 2007, QUT Brisbane.

Duffield, L. (2004). QUT's international radio reporting field trips. In Price-Davies E., et al. Review of Radio Studies Teaching, The Radio Journal: International Studies in Broadcast and Audio Media, 2(2), pp. 120-122.

Deuze, M. (2009) Global journalism education. In De Beer, A. (Ed.), Global Journalism: Topical Issues and Media Systems, (5th edition) (pp. 131-143). Boston : Pearson, Allyn and Bacon.

Frost C. (2010). Reporting for journalists. Oxford: Taylor \& Francis.

Grace, D., \& Cohen, S. (1988). Business ethics: Australian problems and cases, (2nd edition). Melbourne: OUP.

Hannerz, U. (2004). Foreign news: Exploring the world of foreign correspondents. Chicago: University of Chicago Press.

Hirst, M. \& Patching, R. (2007). Journalism ethics: arguments and cases. Melbourne: OUP.

Horine, G.M. (2005). Absolute beginner 's guide to projectmanagement. Indianapolis: Que.

Keleher P., Patil A. \& R.E. Harreveld (2011) (eds.). Work-integrated learning in engineering, built environment and technology: Diversity of practice in practice. Hershey, PA: Information Science Reference, c2011.

Knight, J. (2013). International education hubs: Student, talent, knowledge, innovation models. Dordrecht: Springer, 2013.

Knight J. (2003), Higher education and trade agreements: What are the policy implications? In Breton G. \& M. Lambert (Eds.), Universities and Globalisation:

Private linkages, private trust. Paris, UNESCO

Lim A.H. \& R. Saner (2011). Trade in education services: Market opportunities and risks. Lifelong Learning in Europe, 1, 2011.

Orrell, J. (2005). Management and educational quality of work integrated learning programmes. Opening address at work integrated learning symposium, Griffith University, Australia, November.

Patrick, C., Peach, D., Pocknee, C., Webb, F., Fletcher, M., \& G. Pretto (2008). The WIL (Work Integrated Learning) report: A national scoping study (Final Report). Brisbane: Queensland University of Technology.

Pearson M. (2004), The journalist's guide to media law. Sydney: Allen and Unwin.

Puccio G.J. (1999). Teams. In M.A. Runco, Encyclopaedia of Creativity (pp. 639649). San Diego: Academic Press.

Tanner S., Phillips G., Smyth C. \& S. Tapsell, Journalism ethics at work. Sydney: Pearson.

Woolley, B. (2013). WIL-power: Developing journalism students' intercultural and international reporting skills on a field trip to Vietnam [Unplublished monograph]. Brisbane. 
Dr Lee Duffield is a senior lecturer in Journalism at the Queensland University of Technology, Brisbane, Australia. His research interests are in European media, internationalisation in journalism education, new media, and development news notably in the Asia-Pacific Region. A journalist for over 20 years with the Australian $A B C$, he was the first news editor on the Triple-Jay youth network, and European correspondent at the time of the fall of the Berlin Wall. I.duffield@qut.edu.au

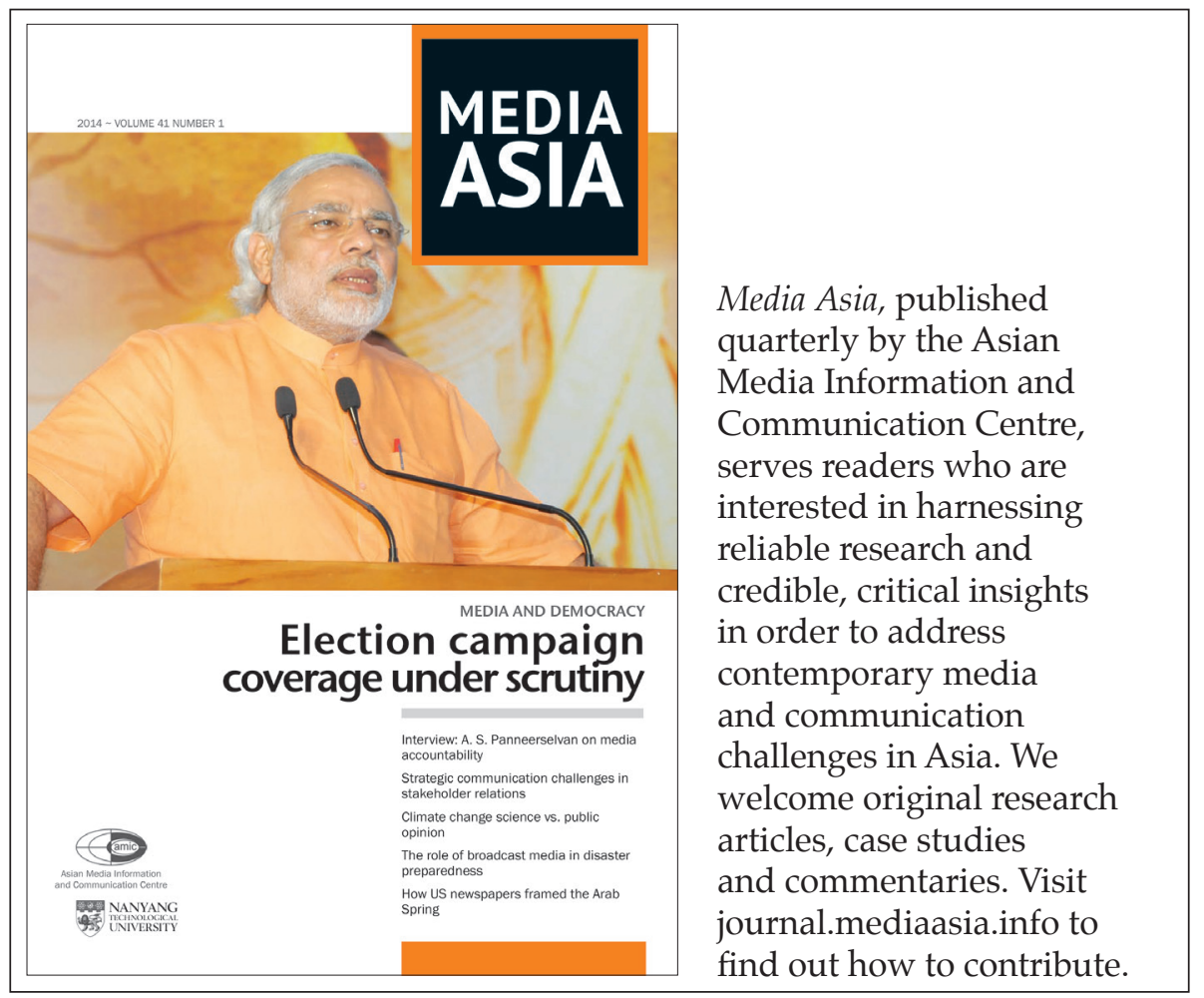

PACIFIC JOURNALISM REVIEW 20 (2) 2014223 